\title{
A network meta-analysis for toxicity of eight chemotherapy regimens in the treatment of metastatic/advanced breast cancer
}

\author{
Xiao-Hua Zhang ${ }^{1}$, Shuai Hao ${ }^{1}$, Bo Gao ${ }^{1}$, Wu-Guo Tian ${ }^{1}$, Yan Jiang ${ }^{1}$, Shu Zhang ${ }^{1}$, \\ Ling-Ji Guo ${ }^{1}$, Dong-Lin Luo ${ }^{1}$ \\ ${ }^{1}$ Department of Breast, Thyroid Surgery, Research Institute of Surgery, Daping Hospital, Third Military Medical University, \\ Chongqing 400042, P.R. China
}

Correspondence to: Dong-lin Luo, email: luodonglin50@163.com

Keywords: metastatic/advanced breast cancer, chemotherapy, toxicity, randomized controlled trials, bayesian network model

Received: June 08, 2016

Accepted: October 17, 2016

Published: November 02, 2016

\section{ABSTRACT}

Objective: To compare the incidence of toxicity of 8 different chemotherapy regimens, including doxorubicin + paclitaxel, doxorubicin, capecitabine, CMF (cyclophosphamide + methotrexate + 5-fluorouracil), FAC (fluorouracil + doxorubicin + cyclophosphamide), doxorubicin + docetaxel, doxorubicin + cyclophosphamide and paclitaxel in the treatment of metastatic/advanced breast cancer.

Results: This network meta-analysis included 8 randomized controlled trials (RCTs). The findings revealed that, with regard to capecitabine alone regimen exhibited higher incidence of nausea/vomiting than doxorubicin + paclitaxel regimen, doxorubicin alone regimen and paclitaxel alone regimen in the treatment of patients with metastatic/advanced breast cancer $(O R=32.48,95 \% \mathrm{CI}=1.65 \sim 2340.57$; OR $=22.75,95 \% \mathrm{CI}=1.03 \sim 1923.52 ; \mathrm{OR}=59.63,95 \% \mathrm{CI}=2.22 \sim 5664.88$, respectively). Furthermore, doxorubicin + cyclophosphamide regimen had lower incidence of febrile neutropenia than doxorubicin + docetaxel $(O R=0.17,95 \%$ $\mathrm{CI}=0.03 \sim 0.96$ ). No significant difference in the incidence of stomatitis was observed among eight chemotherapy regimens.

Materials and methods: We initially searched PubMed, Cochrane Library and Embase databases from the founding of these databases to January 2016. Eligible studies investigating the 8 different chemotherapy regimens for treatment of metastatic/advanced breast cancer were included for direct and indirect comparison. The odds ratio (OR) and surface under the cumulative ranking curves (SUCRA) value of the incidence of toxicity among eight chemotherapy regimens were analyzed.

Conclusions: Capecitabine alone regimen and doxorubicin + docetaxel regimen may have a more frequent toxicity in the treatment of metastatic/advanced breast cancer.

\section{INTRODUCTION}

Breast cancer, one of the most common malignancies worldwide, comprises $3 \%$ of all cancers in women worldwide [1]. Approximately 1.7 million women were diagnosed with breast cancer and 522,000 women were died of this disease in 2012 [2]. In China, the incidence rate of breast cancer rose by five times from 1980 to 2011, from $6.4 / 100,000$ to $31.93 / 100,000$ [3]. The 5-year survival rates of patients with breast cancer were $83.3 \%$, respectively
$97.1 \%$ in stage I but only $24.5 \%$ in stage IV [4]. Lack of effective treatments against invasion and metastasis of breast cancer made it more difficult to increase the survival rate and quality of life in breast cancer patients [5]. Therefore, it is of great importance to identifying novel drugs/compounds with an anti-invasive potential, helping to control the metastasis of cancer cells, and hopefully, searching for novel anticancer drugs or compounds.

At present, chemotherapy plays a crucial part in the comprehensive treatment of breast cancer and 
various types of drugs are implied in the therapy, including docetaxel which can modify tumor phenotype, making tumor cells more amenable to $\mathrm{T}$ cell-mediated killing [6]. Paclitaxel has been reported to have a wide variety of anti-tumor activity following in vivo screens in laboratory mice implanted tumors and also found to possess cytotoxic activity in clinical application [7]. Also, doxorubicin is shown to trigger dose-dependent cardiotoxicity by redox cycling as well as the generation of reactive oxygen species [8]. A previous study has demonstrated that docetaxel combined with doxorubicin can double the clinical complete response rate for breast cancer patients diagnosed with negative axillary nodes [9]. Gemcitabine, an antimetabolite drug and a strong and specific deoxycytidine analog, have antitumor activity and tolerability in pancreatic cancer, lung cancer, ovarian cancer, as well as metastatic breast cancer $[10,11]$. In addition, different combinations of drugs were often used to strengthen the anti-cancer effects and reduce the side effects. For instance, doxorubicin and cyclophosphamide combination therapy, one of various optional choices, being widespread used in patients with an indication for chemotherapy, is used as an effective therapy for earlystage breast cancer [12]. Moreover, cyclophosphamide, a common anticancer drug for breast tumor, was often used as a compound with other drugs, including cyclophosphamide + methotrexate +5 -fluorouracil (CMF), fluorouracil + doxorubicin + cyclophosphamide (FAC), Doxorubicin + Cyclophosphamide [13]. However, the optimal regime for advanced breast cancer remains undetermined.

In the last decade, network meta-analysis of randomized controlled trials (RCTs) whose advantage lie in facilitating indirect comparisons of multiple interventions, has been introduced as an extension of pairwise meta-analysis [14]. Unlike traditional metaanalysis, network meta-analysis is capable of indirect comparison not only by utilizing a common comparator to avoid the embarrassment of head-to-head experiment failure but also uniting both direct and indirect comparisons simultaneously $[15,16]$. In this network meta-analysis, we aimed to compare the incidence of toxicity of different chemotherapy regimens in the treatment of metastatic/advanced breast cancer.

\section{RESULTS}

\section{Characteristics of included studies}

A total of 2155 publications were initially retrieved in this study, and 133 for repeated assays, 157 for letters or summaries, 320 for non-human studies, and 319 for non-English papers were eliminated. Moreover, 455 for non-RCT studies, 248 articles unrelated to breast cancer, 512 articles unrelated to chemotherapy, 3 articles without data or incomplete data were also rejected from the rest of 1226 assays. Finally, eight RCTs met the inclusion criteria and were selected into our meta-analysis from 2001 to 2014 [17-24] (Supplementary Figure S1). A total of 2218 patients with metastatic/advanced breast cancer were recruited into meta-analysis, among which the majority of patients were treated with doxorubicin + paclitaxel chemotherapy regimen. Seven RCTs were conducted in the Caucasians, and the other RCT was conducted in the Asians. Furthermore, seven included studies were conducted by two-arm trial, and the rest 1 by three-arm trial. The characteristics of included studies were summarized in Table 1 and Cochrane risk of bias assessment in Figure 1.

\section{Pairwise meta-analysis}

We conducted a direct comparison of the incidence of toxicity of 8 chemotherapy regimens during the treatment of metastatic/advanced breast cancer, and the results were as follows: in terms of nausea/vomiting, doxorubicin + docetaxel chemotherapy showed higher incidence of toxicity compared with doxorubicin + cyclophosphamide chemotherapy $(\mathrm{OR}=3.38,95 \% \mathrm{CI}=1.80 \sim 6.34)$; the incidence of toxicity was correspondingly higher in the patients undergoing doxorubicin chemotherapy than paclitaxel chemotherapy $(\mathrm{OR}=2.67,95 \% \mathrm{CI}=1.02 \sim 7.00)$; when compared with doxorubicin + cyclophosphamide and FAC chemotherapy, doxorubicin + paclitaxel chemotherapy delivered a lower incidence of toxicity $(\mathrm{OR}=0.33$, $95 \% \mathrm{CI}=0.15 \sim 0.73 ; \mathrm{OR}=0.39,95 \% \mathrm{CI}=0.18 \sim 0.82$, respectively). Concerning stomatitis, the incidence of toxicity of CMF chemotherapy was stronger than FAC chemotherapy $(\mathrm{OR}=10.70,95 \% \mathrm{CI}=1.31 \sim 87.19)$. Regarding febrile neutropenia, the incidence of toxicity of doxorubicin + docetaxel chemotherapy was higher than doxorubicin + cyclophosphamide chemotherapy $(\mathrm{OR}=3.58,95 \% \mathrm{CI}=2.10 \sim 6.11)$; the incidence of toxicity of doxorubicin + paclitaxel chemotherapy was stronger in comparison with doxorubicin + cyclophosphamide chemotherapy $(\mathrm{OR}=4.74,95 \% \mathrm{CI}=2.37 \sim 9.49)$; the incidence of toxicity of doxorubicin + paclitaxel chemotherapy was lower than doxorubicin + docetaxel chemotherapy $(\mathrm{OR}=0.29,95 \% \mathrm{CI}=0.16 \sim 0.53)$ (Supplementary Table S1).

\section{Evidential network}

Eight chemotherapy regimens were included in this study: doxorubicin + paclitaxel, doxorubicin, capecitabine, CMF (cyclophosphamide + methotrexate +5 fluorouraci), FAC (fluorouracil+doxorubicin + cycloph osphamide), doxorubicin + docetaxel, doxorubicin + cyclophosphamide, and paclitaxel. In terms of nausea/ vomiting, stomatitis and febrile neutropenia, a largest number of patients received doxorubicin + paclitaxel chemotherapy, while the least number of patients received capecitabine chemotherapy regimen (Figure 2). 
Table 1: The baseline characteristics for included studies

\begin{tabular}{|c|c|c|c|c|c|c|c|c|c|c|c|c|c|c|}
\hline \multirow{2}{*}{ First author } & \multirow{2}{*}{ Year } & \multirow{2}{*}{ Country } & \multicolumn{3}{|c|}{ Interventions } & \multicolumn{3}{|c|}{ Sample size } & \multicolumn{4}{|c|}{ Age (years) } & \multirow{2}{*}{$\begin{array}{c}\text { Disease } \\
\text { stage }\end{array}$} & \multirow{2}{*}{$\begin{array}{l}\text { Median } \\
\text { follow-up } \\
\text { (months) }\end{array}$} \\
\hline & & & T1 & $\mathbf{T 2}$ & T3 & Total & T1 & $\mathbf{T 2}$ & T3 & T1 & $\mathbf{T} 2$ & T3 & & \\
\hline Smorenburg $\mathrm{CH}$ & 2014 & Netherlands & B & $\mathrm{C}$ & & 78 & 40 & 38 & & - & - & & Stage IV & 39 \\
\hline Leone JP & 2014 & America & $\mathrm{D}$ & $\mathrm{E}$ & & 126 & 62 & 64 & & $54(31-74)$ & $51(24-75)$ & & Stage III & 54 \\
\hline Stockler MR & 2011 & Australia & $\mathrm{C}$ & $\mathrm{D}$ & & 216 & 107 & 109 & & - & - & & Stage IV & 39.6 \\
\hline Cassier PA & 2008 & France & A & $\mathrm{F}$ & & 210 & 103 & 107 & & $58(32-79)$ & $56(32-79)$ & & Stage IV & 50.2 \\
\hline Evans TR & 2005 & UK & $\mathrm{F}$ & G & & 363 & 183 & 180 & & $49(27-74)$ & $48(25-73)$ & & Stage IV & 32 \\
\hline Sledge GW & 2003 & India & A & B & $\mathrm{H}$ & 683 & 230 & 224 & 229 & $56(27-76)$ & $56(27-78)$ & $56(25-79)$ & Stage IV & 26 \\
\hline Biganzoli L & 2002 & France & $\mathrm{A}$ & G & & 275 & 138 & 137 & & $52(29-70)$ & $54(28-70)$ & & Stage IV & 29.2 \\
\hline Jassem J & 2001 & Poland & A & $\mathrm{E}$ & & 267 & 134 & 133 & & $50(33-70)$ & $50(24-74)$ & & Stage IV & 29 \\
\hline
\end{tabular}

Notes: $\mathrm{T}=$ Treatment; $\mathrm{M}=$ male $\mathrm{F}=$ female; $\mathrm{A}=$ Doxorubicin + Paclitaxel $\mathrm{B}=$ Doxorubicin $; \mathrm{C}=\mathrm{Capecitabine} ; \mathrm{D}=\mathrm{CMF}($ cyclophosphamide + methotrexate + 5-fluorouracil); E = FAC (fluorouracil + doxorubicin + cyclophosphamide); F = Doxorubicin + Docetaxel; G = Doxorubicin + Cyclophosphamide; $\mathrm{H}=$ Paclitaxel.

\section{Tests of discordancy}

The nausea/vomiting, stomatitis and febrile neutropenia outcomes were analyzed by discordancy test with the node-splitting method, and the analysis showed that all outcomes of the direct and indirect evidence are consistent, thus the consistency model should be adopted (all $P>0.05$ ) (Table 2).

\section{Network meta-analysis}

As Supplementary Table S2 and Figure 3 indicated, concerning nausea/vomiting, capecitabine chemotherapy exhibited higher toxicity when compared with doxorubicin + paclitaxel, doxorubicin, and paclitaxel chemotherapy regimens $(\mathrm{OR}=32.48,95 \% \mathrm{CI}=1.65 \sim 2340.57 ; \mathrm{OR}=22.75$, $95 \% \mathrm{CI}=1.03 \sim 1923.52 ; \mathrm{OR}=59.63,95 \% \mathrm{CI}=2.22$, 5664.88 , respectively). When compared with doxorubicin + docetaxel chemotherapy, the incidence of toxicity of doxorubicin + cyclophosphamide chemotherapy was lower with regard to febrile neutropenia $(\mathrm{OR}=0.17$, $95 \% \mathrm{CI}=0.03 \sim 0.96$ ). However, no significance was shown in the incidence of toxicity of each chemotherapy regimen as for stomatitis.

\section{Cumulative probability}

As shown in Table 3, the SUCRA values demonstrated that paclitaxel chemotherapy ranked the highest $(92.3 \%)$, while capecitabine chemotherapy ranked the lowest $(16.1 \%)$ with regard to nausea/vomiting. However capecitabine chemotherapy regimen ranked the highest (76.8\%) and CMF chemotherapy ranked the lowest $(26.2 \%)$ concerning stomatitis. As for febrile neutropenia, doxorubicin + cyclophosphamide chemotherapy ranked the highest $(96.0 \%)$ and doxorubicin + docetaxel ranked the lowest $(39.7 \%)$. In a meta-regression analysis to assess potential bias, no significant difference was found

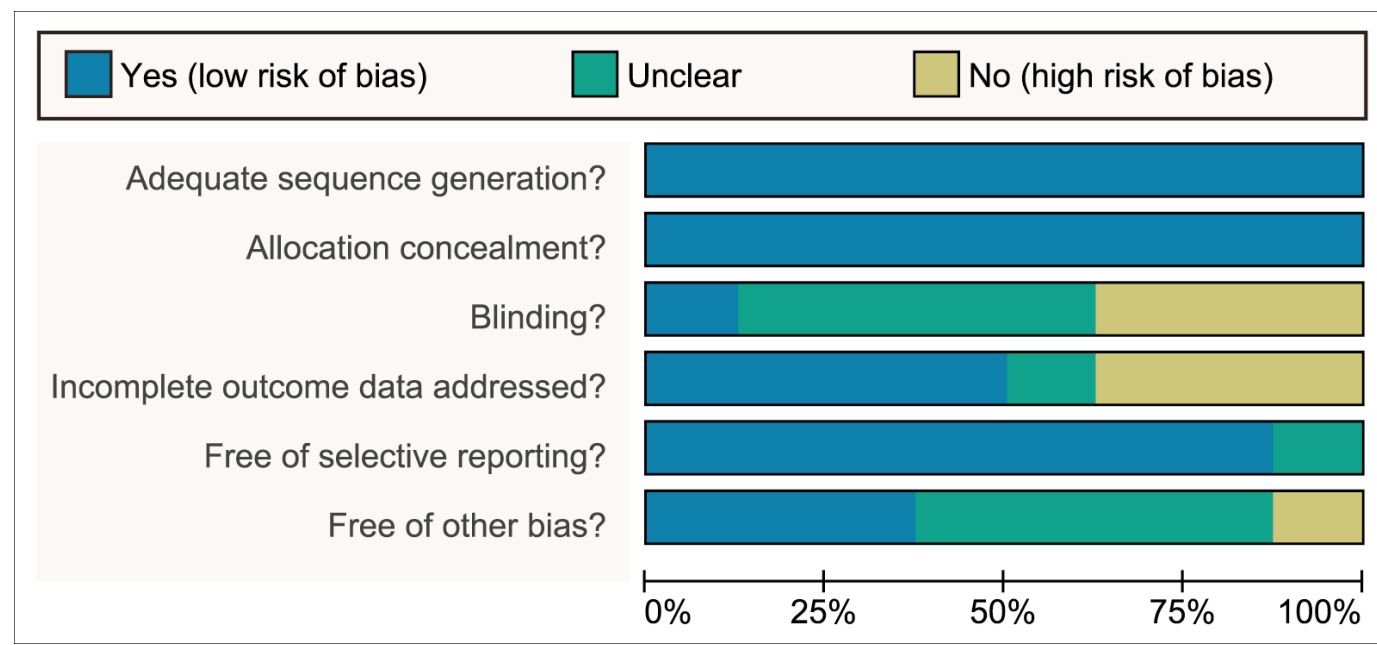

Figure 1: More than 2 reviewers evaluated the quality of randomized controlled trial with a modified Cochrane risk of bias assessment tool. 
Table 2 :OR values and $P$ values of direct and indirect pairwise comparisons of eight treatment modalities under three endpoint outcomes

\begin{tabular}{|c|c|c|c|c|c|c|c|c|c|}
\hline \multirow{2}{*}{ Pairwise comparisons } & \multicolumn{3}{|c|}{ Direct OR values } & \multicolumn{3}{|c|}{ Indirect OR values } & \multicolumn{3}{|c|}{$P$ values } \\
\hline & Nau & Sto & Feb & Nau & Sto & Feb & Nau & Sto & Feb \\
\hline B vs A & 1.70 & 1.80 & NR & 0.003 & 11.0 & NR & 0.335 & 0.651 & NR \\
\hline E vs A & 2.60 & 0.97 & NR & 4.30 & 0.20 & NR & 0.413 & 0.660 & NR \\
\hline F vs A & 2.80 & NR & 3.50 & 1.40 & NR & 0.72 & 0.576 & $\mathrm{NR}$ & 0.246 \\
\hline G vs A & 3.20 & NR & 0.21 & 6.40 & NR & 0.99 & 0.605 & NR & 0.270 \\
\hline C vs B & 1.40 & 0.18 & NR & 12.0 & 0.77 & NR & 0.398 & 0.648 & NR \\
\hline D vs $C$ & 0.18 & 9.40 & NR & 0.004 & 57.00 & NR & 0.353 & 0.654 & NR \\
\hline E vs D & 0.67 & 0.068 & NR & 0.004 & 0.360 & NR & 0.379 & 0.618 & NR \\
\hline G vs F & 2.40 & NR & 0.27 & 1.20 & NR & 4.20 & 0.656 & NR & 0.264 \\
\hline
\end{tabular}

Notes: $\mathrm{NR}=$ Not report; OR $=$ odds ratio; Nau $=$ Nausea/vomiting; Sto $=$ Stomatitis; Feb $=$ Febrile neutropenia; $\mathrm{A}$ $=$ Doxorubicin + Paclitaxel; $\mathrm{B}=$ Doxorubicin; $\mathrm{C}=$ Capecitabine; $\mathrm{D}=\mathrm{CMF}$ (cyclophosphamide + methotrexate + 5-fluorouracil); E = FAC (fluorouracil + doxorubicin + cyclophosphamide); F = Doxorubicin + Docetaxel; G = Doxorubicin + Cyclophosphamide; $\mathrm{H}=$ Paclitaxel.

Table 3: SUCRA values of eight treatment modalities under three endpoint outcomes

\begin{tabular}{cccc}
\hline \multirow{2}{*}{ Treatments } & \multicolumn{3}{c}{ SUCRA values } \\
\cline { 2 - 4 } & Nausea/vomiting & Stomatitis & Febrile neutropenia \\
\hline A & 0.820 & 0.612 & 0.647 \\
B & 0.673 & 0.413 & NR \\
C & $\mathbf{0 . 1 6 1}$ & 0.768 & NR \\
D & 0.399 & $\mathbf{0 . 2 6 2}$ & NR \\
E & 0.506 & 0.720 & $\mathrm{NR}$ \\
F & 0.623 & $\mathrm{NR}$ & $\mathbf{0 . 3 9 7}$ \\
G & 0.394 & $\mathrm{NR}$ & 0.960 \\
H & 0.923 & 0.720 & $\mathrm{NR}$ \\
\hline
\end{tabular}

Notes: SUCRA $=$ Surface under the cumulative ranking curves; NR $=$ Not report; $\mathrm{A}=$ Doxorubicin + Paclitaxel; $\mathrm{B}=$ Doxorubicin; $\mathrm{C}=$ Capecitabine; $\mathrm{D}=\mathrm{CMF}$ (cyclophosphamide + methotrexate +5 -fluorouracil); $\mathrm{E}=\mathrm{FAC}$ (fluorouracil + doxorubicin + cyclophosphamide); F = Doxorubicin + Docetaxel; G = Doxorubicin + Cyclophosphamide; H = Paclitaxel.

in the SUCRA values of eight chemotherapy regimens under three outcome measures after considering covariate (median follow-up: $P=0.314$, disease stage: $P=0.980$ ), thus the median follow-up and disease stage were not the main source of heterogeneity (Table 4)

\section{DISCUSSION}

After collecting historical cases and analyzing 8 different chemotherapy regimens for metastatic/advanced breast cancer by pairwise and network meta-analysis, we found evidence that capecitabine regimen showed stronger toxicity in the treatment of metastatic/advanced breast cancer, while the incidence of toxicity of doxorubicin + paclitaxel, doxorubicin, paclitaxel, doxorubicin + docetaxel regimens were relatively lower.

The analysis of pairwise and network meta-analysis consistently indicated that the incidence of toxicity of capecitabine regimen was higher than other regimens during the treatment of metastatic/advanced breast cancer. As an orally administered chemotherapy of fluorouracil, capecitabine shows antineoplasmic activity in various models, which is activated metabolically at the tumor site [25]. Besides, capecitabine is primarily transformed into 5 '-deoxy-5-fluorocytidine in the liver, and further into 5'-deoxy-5-fluorouridine (5'-DFUR). Subsequently, $5^{\prime}$-DFUR is metabolized to active 5-FU by thymidine phosphorylase (TP), and higher concentration of TP is present in some tumor tissues in comparison with normal tissues [26, 27]. As several studies indicated, capecitabine treatment has confirmed its efficacy and activity in metastatic/advanced breast cancer [28-31]. However, hand-foot syndrome (HFS), a common side-effect and dose-limiting toxicity, often results from capecitabine treatment for patients with metastatic/advanced breast cancer, which seriously affects patients' daily activity 
and life quality $[32,33]$. While the pathogenesis of HFS is not completely clear, which may be associated with enzymes involved in capecitabine metabolism, and the high activity of dihydropyrimidine dehydrogenas (DPD) and TP contribute to metabolite accumulation of capecitabine [34]. On the other hand, Saher et al. points out that capecitabine eliminates from the eccrine gland system, thus the increased number of eccrine glands in hand and foot may play a key role in HFS pathogenesis [35]. Meanwhile, Stockler et al. has proven that, although febrile neutropenia, infection, stomatitis, and serious adverse events were more common with CMF, HFS presented higher frequency on metastatic/advanced breast cancer receiving capecitabine treatment than CMF [19].

On the other hand, the pairwise and network metaanalysis also revealed that four chemotherapy regimens displayed lower toxicity in metastatic/advanced breast cancer patients (doxorubicin + paclitaxel, doxorubicin, paclitaxel, doxorubicin + docetaxel). As an anthracycline antibiotic, doxorubicin is one of the most effective chemotherapeutics widely used for the treatment of breast cancer [36]. Additionally, the polymer-doxorubicin can cause decreased plasma concentration by sustaining the release of anti-neoplastic drugs, which may reveal the
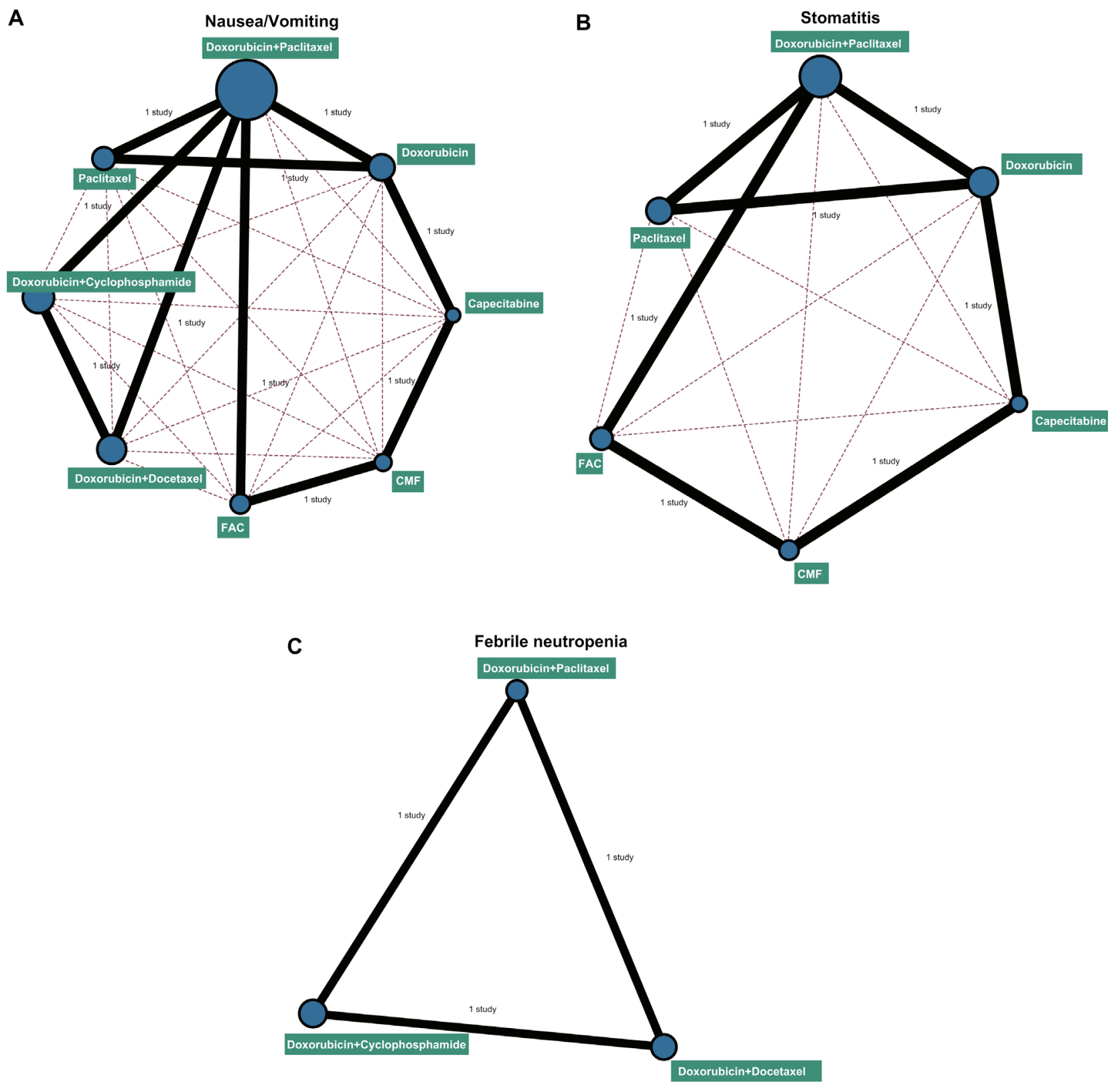

Figure 2: Network diagrams of the incidence of nausea/vomiting, stomatitis and febrile neutropenia. Note: (A) nausea/ vomiting; (B) stomatitis; (C) febrile neutropenia; CMF: cyclophosphamide + methotrexate +5 -fluorouraci; FAC: fluorouracil + doxorubicin + cyclophosphamide. The width of the lines is proportional to the number of trials comparing every pair of treatments, and the size of every circle is proportional to the number of randomly assigned participants (sample size). 
association with the dose-limiting cardiotoxicity [37]. As studies reported, liposomal doxorubicin has exhibited diminished the cardiac toxicity in various clinical tests, and the combination of pegylated liposomal doxorubicin and other anti-tumor drugs was positive against metastatic/advanced breast cancer [38-40]. Belonging to taxane drugs category, paclitaxel specially binds to $\beta$-tubulin subunit of the N-terminal in the microtubule fasolculus and inhibits its growth and cell replication [7]. Furthermore, paclitaxel also shows the unique ability to restrain the proliferation and migration of tumor cells [41]. Hence, the lower toxicity of paclitaxel is reasonable due to its specific therapeutic targets. For patients with metastatic triple-negative breast cancer, cisplatin + gemcitabine regimen might be an alternative or even the favorable first-line chemotherapy strategy when compared with the more established paclitaxel + gemcitabine regimen [42]. For women with metastatic breast cancer, doxorubicin and paclitaxel as first-line therapy has an obvious advantage over FAC in the aspects of response rate, median time
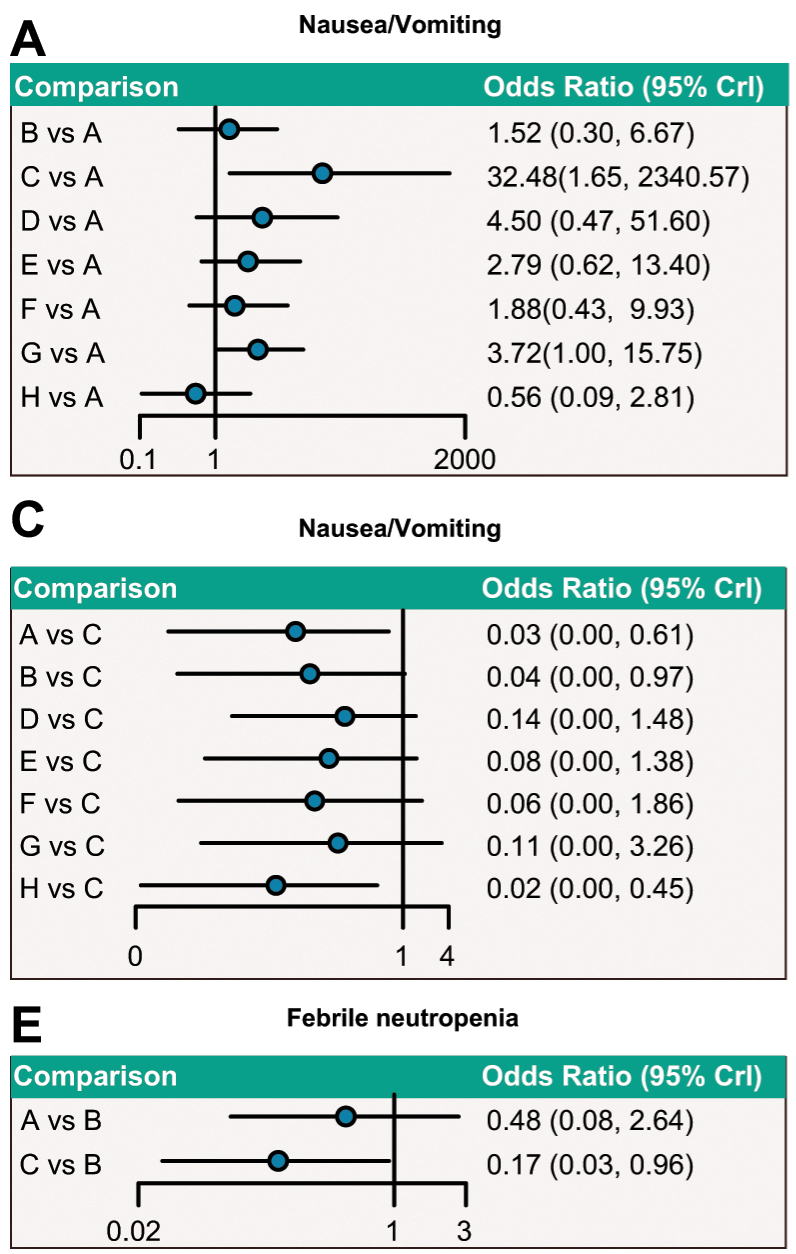

to progression, as well as in overall survival [43]. In elderly metastatic breast cancer patients, the first-line single-agent chemotherapy of both pegylated liposomal doxorubicin and capecitabine showed comparable efficacy and acceptable tolerance [17]. In terms of docetaxel, this chemotherapy possesses a variety of advantages on the treatment of metastatic/advanced breast cancer, but it is followed by severe side effects including anemia, neuropathy and asthenia, myelosuppression, and hypersensitivity reaction [44]. With the development of nanotechnology, the use of nanoparticle drug can prevent side effects following docetaxel and reduce docetaxel toxicity [45]. Interestingly, Sledge et al. confirms that single treatments of doxorubicin and paclitaxel regimens exhibit lower toxicity than doxorubicin + paclitaxel therapy [22]. As mentioned above, the lower toxicities of doxorubicin, paclitaxel and docetaxel have been reported, thus the interaction between the combination of doxorubicin + paclitaxel, and doxorubicin + docetaxel contribute to the less toxicity in breast cancer. Cassier PA
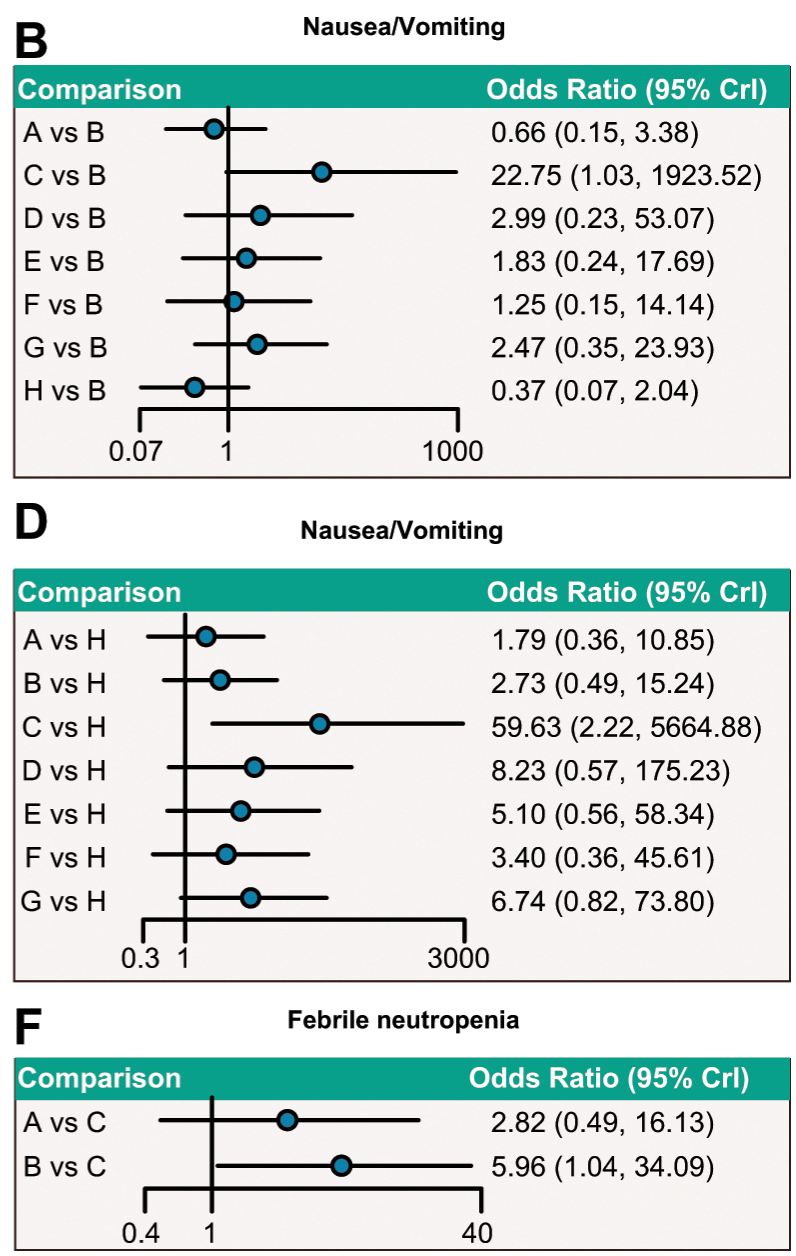

Figure 3: Relative network diagrams of the incidence of nausea/vomiting and febrile neutropenia. Note: nausea/vomiting: $\mathrm{A}=$ doxorubicin + paclitaxel; $\mathrm{B}=$ doxorubicin; $\mathrm{C}=$ capecitabine; $\mathrm{D}=\mathrm{CMF}$ (cyclophosphamide + methotrexate +5 -fluorouraci); $\mathrm{E}=\mathrm{FAC}$ (fluorouracil + doxorubicin + cyclophosphamide); $\mathrm{F}=$ doxorubicin + docetaxel; $\mathrm{G}=$ doxorubicin + cyclophosphamide; $\mathrm{H}=$ paclitaxel; Ffebrile neutropenia: $\mathrm{A}=$ doxorubicin + paclitaxel; $\mathrm{B}=$ doxorubicin + docetaxel; $\mathrm{C}=$ doxorubicin + cyclophosphamide; CrI: Credible interval; The confidence interval of OR passes through 1 , indicating no significance. 
Table 4: SUCRA values of eight chemotherapy regimens under three outcome measures after considering covariate

\begin{tabular}{ccc}
\hline \multirow{2}{*}{ Treatments } & \multicolumn{2}{c}{ SUCRA values (considering covariate) } \\
\cline { 2 - 3 } A & Median follow-up & Disease stage \\
\hline B & $\mathbf{0 . 7 9 3}$ & $\mathbf{0 . 7 9 8}$ \\
C & 0.542 & 0.530 \\
D & 0.228 & 0.226 \\
E & 0.485 & 0.488 \\
F & 0.537 & 0.544 \\
G & 0.645 & 0.646 \\
H & 0.397 & 0.401 \\
\hline
\end{tabular}

Notes: SUCRA $=$ Surface under the cumulative ranking curves; $\mathrm{A}=$ Doxorubicin + Paclitaxel; $\mathrm{B}=$ Doxorubicin; $\mathrm{C}=$ Capecitabine $; \mathrm{D}=\mathrm{CMF}$ (cyclophosphamide + methotrexate +5 -fluorouracil) $; \mathrm{E}=\mathrm{FAC}($ fluorouracil + doxorubicin + cyclophosphamide); $\mathrm{F}=$ Doxorubicin + Docetaxel; $\mathrm{G}=$ Doxorubicin + Cyclophosphamide; $\mathrm{H}=$ Paclitaxel.

et al. supported that in the treatment of metastatic breast cancer, the combinations of paclitaxel + doxorubicin and docetaxel + doxorubicin have shown superiority over other treatments; doxorubicin combined with docetaxel or paclitaxel have yield similar results in the treatment of metastatic breast cancer, but these two ways of combinations have induced different toxicities because of the specific toxicity profile [20].

In our study, we adapted the combined analysis of pairwise and network, and the application of the nodesplitting method aimed to verify direct and indirect outcomes, which can compare a variety of interventions, thus more accurate and comprehensive conclusions were obtained [46]. However, it must note that the experiment was relatively single due to small included number of articles and lack of contrast between the cross-research projects, resulting in restriction of universal conclusion. Moreover, with regard to febrile neutropenia, the involved assays did not include doxorubicin, capecitabine, CMF, FAC, and paclitaxel chemotherapy, thus it fail to be analyzed in the calculation of SCRUA value. And nausea/ vomiting, the amount of interventions related to nausea/ vomiting, stomatitis and febrile neutropenia outcomes were not equal, so the cluster analysis fails to be in progress, which may result in the appearance of subtle bias. Furthermore, other side effects were not included in the study because of insufficient enrolled literatures and chemotherapy incapable of forming rings. Nevertheless, major cases are enrolled in the study, and consistent with the research progress, hence the conclusion has certain value and significance.

In conclusion, these results indicate that capecitabine alone regimen and doxorubicin + docetaxel regimen may have a more frequent toxicity in the treatment of metastatic/advanced breast cancer, which has a certain guiding significance for the clinical use and treatment of metastatic/advanced breast cancer.

\section{MATERIALS AND METHODS}

\section{Search strategy}

Computer-based retrieval in PubMed, the Cochrane Library, and Embase English databases (from inception to January 2016), combined with manual retrieval of related references were performed. Combining the keywords and free words, the searches terms were as followed: chemotherapy, cyclophosphamide, doxorubicin, docetaxel, capecitabine, gemcitabine, advanced breast cancer, as well as RCT.

\section{Pubmed search strategy}

\#1: "breast neoplasms"[mh] OR breast cancer[tiab] OR Neoplasm, Breast[tiab] OR Tumors, Breast OR Mammary Neoplasms, Human[tiab] OR Human Mammary Neoplasm[tiab] OR Mammary Carcinoma, Human[tiab] OR Carcinomas, Human Mammary[tiab] OR Mammary Carcinomas, Human[tiab] OR Mammary Cancer[tiab] OR Cancer of Breast[tiab]

\#2: chemotherapy[tiab] OR "Cyclophosphamide" [mh] OR "Doxorubicin"[mh] OR Farmiblastina[tiab] OR "Paclitaxel"[mh] OR "Docetaxel"[mh] OR "Capecitabine" [mh] OR "gemcitabine" [mh] OR "Epothilone"[mh] OR "vinorelbine"[Supplementary Concept] OR "DDP" [Supplementary Concept] OR "Carboplatin" [Supplementary Concept] OR "oxaliplatin"[Supplementary Concept] OR "Pirarubicin"[Supplementary Concept] OR "Epirubicin"[mh]

\#3: "randomized controlled trial"[pt] OR "controlled clinical trial" [pt] OR "randomized controlled trials as topic"[Mesh] OR "clinical trials as topic"[mh] OR "controlled clinical trials as topic"[mh] OR placebos[mh] OR "random allocation"[mh] OR "double-blind method"[mh] OR randomized[tiab] OR placebo[tiab] 
OR randomization[tiab] OR randomly allocated[tiab] OR ((double[tw] OR treble[tw] OR triple[tw]) AND (mask* [tw] OR blind* [tw]))

\#4: \#1 and \#2 and \#3

\section{Selection criteria}

The inclusion criteria: (1) study type: RCT; (2) interventions: doxorubicin + paclitaxel, doxorubicin, capecitabine, CMF (cyclophosphamide + methotrexate + fluorouraci), FAC (fluorouracil + doxorubicin + cyclophosphamide), doxorubicin + docetaxel, doxorubicin + cyclophosphamide, and paclitaxel; (3) chemotherapy: first-line therapy; (4) disease stage: stage III or IV; (5) patient population: hospital-based patient; (6) subjects: at least one measurable lesion in patients with metastatic/ advanced breast cancer according to the Response Evaluation Criteria in Solid Tumors (RECIST) [47]; (7) outcomes: patients with nausea/vomiting, stomatitis, and febrile neutropenia. The exclusion criteria: (1) breast cancer patients with inflammatory reaction; (2) patients undergoing systemic and radiation therapy; (3) patients with other serious diseases or mental illness history; (4) patients with chronic liver disease; (5) incomplete literature data (for example: non-matched pair study); (6) non RCT; (7) duplications; (8) conference report, systems assessment and abstract; (9) non-English literature; (10) non-human study.

\section{Data extraction and quality assessment}

Two reviewers abstracted the data independently with the unified data collection form, and disagreements were resolved by discussion with a number of investigators. The trial size, trial design, details of intervention including treatment duration, patient characteristics such as sex, age, mean duration of follow-up time as well as outcome data were extracted. For crossover trials, the data was extracted from the first period only in order to avoid possible carryover effects. The means and measures of dispersion were approximated from figures in the reports as previously described whenever necessary. Whenever possible, we extracted results from the intention-to-treat analyses. More than 2 reviewers evaluated the quality of RCT with a modified Cochrane risk of bias assessment tool [48], which included the following 6 domains: random assignment, allocation concealment, blinding of participants, incomplete outcome data, selective outcome reporting, and other sources of bias. The RCT assessment was explicitly evaluated as "yes," "no," or "unclear" for each domain to assign a low, high, or unclear risk of bias, respectively. The study was regarded with low risk of bias when one or no domain was defined as "unclear" or "no", the study was regarded with high risk of bias when four or more domains were defined as "unclear" or "no", and the study was regarded with moderate risk of bias when two or three domains were defined as "unclear" or "no" [49]. Quality assessment and investigation of publication bias were conducted by Review Manager 5 (RevMan 5.2.3, Cochrane Collaboration, Oxford, UK).

\section{Statistical methods}

Firstly, pairwise meta-analyses of direct evidence were conducted by the fixed-effects model, with $\mathrm{R}$ version 3.2.1 and the meta-package. We also calculated the pooled results of odd ratios (OR) with 95\% credible intervals (CrIs) of three end point outcomes. Chi-square test and I-square test were carried out for testing heterogeneity among the studies [50]. Then, $\mathrm{R}$ version 3.2.1 and network package were used for drawing the network graph. Besides, each node represented a variety of interventions, the node size represented the sample size, and the lines between the nodes represented the included numbers of research. Also, we implemented a random-effects network meta-analysis with the gemtc package, which modeled the relative effects (e.g.log-odds ratio) responding to a generalized linear model (GLM) under the Bayesian framework by connecting to JAGS, OpenBUGS or WinBUGS as first described by $\mathrm{Lu}$ and Ades [51], and improved by others $[52,53]$. Subsequently, we also adopted the nodesplitting method to evaluate the consistency between direct and indirect evidence, and chosen the consistency or inconsistency model based on the results. If the node segmentation showed that the $P$ value was higher than 0.05 , the consistency model was used to analyze the results [54]. In order to facilitate the interpretation of ORs, we calculated the chance of each intervention that was the optimal treatment method on the basis of a Bayesian approach using probability values summarized as surface under the cumulative ranking curve (SUCRA). The higher the SUCRA value, the better the rank of the intervention $[55,56]$. R 3.2.1 was conducted for all analyses.

\section{ACKNOWLEDGMENTS AND FUNDING}

This work was supported by grants from the National Funding Projects of Science and Technology for Public Wellbeing (2013GS500101-05). We would like to thank the reviewers for their valuable advice.

\section{CONFLICTS OF INTEREST}

Authors state no conflicts of interests.

\section{REFERENCES}

1. Vollebergh MA, Jonkers J, Linn SC. Genomic instability in breast and ovarian cancers: translation into clinical predictive biomarkers. Cell Mol Life Sci. 2012; 69:223-45.

2. Umehara T, Okita Y, Nonaka M, Kanemura Y, Kodama Y, Mano M, Nakajima S, Fujinaka T. A case of pilocytic astrocytoma requiring tumor resection during pregnancy. Mol Clin Oncol. 2016; 4:567-70. 
3. Yan B, Yang LM, Hao LP, Yang C, Quan L, Wang LH, Wu Z, Li XP, Gao YT, Sun Q, Yuan JM. Determinants of Quality of Life for Breast Cancer Patients in Shanghai, China. PLoS One. 2016; 11:e0153714.

4. Macia F, Porta M, Murta-Nascimento C, Servitja S, Guxens M, Buron A, Tusquets I, Albanell J, Castells X. Factors affecting 5- and 10-year survival of women with breast cancer: an analysis based on a public general hospital in Barcelona. Cancer Epidemiol. 2012; 36:554-9.

5. Yan WJ, Ma XC, Gao XY, Xue XH, Zhang SQ. Latest research progress in the correlation between baicalein and breast cancer invasion and metastasis. Mol Clin Oncol. 2016; 4:472-76.

6. Heery CR, Ibrahim NK, Arlen PM, Mohebtash M, Murray JL, Koenig K, Madan RA, McMahon S, Marte JL, Steinberg SM, Donahue RN, Grenga I, Jochems C, et al. Docetaxel Alone or in Combination With a Therapeutic Cancer Vaccine (PANVAC) in Patients With Metastatic Breast Cancer: A Randomized Clinical Trial. JAMA Oncol. 2015; 1:1087-95.

7. Kampan NC, Madondo MT, McNally OM, Quinn M, Plebanski M. Plebanski. Paclitaxel and Its Evolving Role in the Management of Ovarian Cancer. Biomed Res Int. 2015; 2015:413076.

8. Zhang S, Liu X, Bawa-Khalfe T, Lu LS, Lyu YL, Liu LF, Yeh ET. Yeh. Identification of the molecular basis of doxorubicin-induced cardiotoxicity. Nat Med. 2012; 18:1639-42.

9. Bear HD, Anderson S, Smith RE, Geyer CE, Jr., Mamounas EP, Fisher B, Brown AM, Robidoux A, Margolese R, Kahlenberg MS, Paik S, Soran A, Wickerham DL, et al. Sequential preoperative or postoperative docetaxel added to preoperative doxorubicin plus cyclophosphamide for operable breast cancer:National Surgical Adjuvant Breast and Bowel Project Protocol B-27. J Clin Oncol. 2006; 24:2019-27.

10. Jacob DA, Bahra M, Langrehr JM, Boas-Knoop S, Stefaniak R, Davis J, Schumacher G, Lippert S, Neumann UP. Neumann. Combination therapy of poly (ADP-ribose) polymerase inhibitor 3-aminobenzamide and gemcitabine shows strong antitumor activity in pancreatic cancer cells. $\mathrm{J}$ Gastroenterol Hepatol. 2007; 22:738-48.

11. Heinemann V. Role of gemcitabine in the treatment of advanced and metastatic breast cancer. Oncology. 2003; 64:191-206.

12. Bray J, Sludden J, Griffin MJ, Cole M, Verrill M, Jamieson D, Boddy AV. Boddy. Influence of pharmacogenetics on response and toxicity in breast cancer patients treated with doxorubicin and cyclophosphamide. $\mathrm{Br}$ J Cancer. 2010; 102:1003-9.

13. Nakajima $M$, Komagata S, Fujiki Y, Kanada Y, Ebi H, Itoh K, Mukai H, Yokoi T, Minami H. Genetic polymorphisms of CYP2B6 affect the pharmacokinetics/ pharmacodynamics of cyclophosphamide in Japanese cancer patients. Pharmacogenet Genomics. 2007; 17:431-45.
14. Jansen JP, Naci H. Naci. Is network meta-analysis as valid as standard pairwise meta-analysis? It all depends on the distribution of effect modifiers. BMC Med. 2013; 11:159.

15. Sutton A, Ades AE, Cooper N, Abrams K. Abrams. Use of indirect and mixed treatment comparisons for technology assessment. Pharmacoeconomics. 2008; 26:753-67.

16. Liao WC, Chien KL, Lin YL, Wu MS, Lin JT, Wang HP, $\mathrm{Tu}$ YK. Adjuvant treatments for resected pancreatic adenocarcinoma: a systematic review and network metaanalysis. Lancet Oncol. 2013; 14:1095-103.

17. Bamal R, Chintamani, Tandon M, Mittal MK, Saxena S. Evaluation and Validation of Neo-Adjuvant Response Index (NRI) and It's Correlation with Various Predictive Biomarkers and RECIST in Locally Advanced Breast Cancer. Indian J Surg Oncol. 2014; 5:171-7.

18. Higgins JP, Altman DG, Gotzsche PC, Juni P, Moher D, Oxman AD, Savovic J, Schulz KF, Weeks L, Sterne JA, Cochrane Bias Methods G, Cochrane Statistical Methods G. The Cochrane Collaboration's tool for assessing risk of bias in randomised trials. BMJ. 2011; 343:d5928.

19. Chung JH, Lee SW. Assessing the quality of randomized controlled urological trials conducted by korean medical institutions. Korean J Urol. 2013; 54:289-96.

20. Minami S, Kijima T, Shiroyama T, Okafuji K, Hirashima T, Uchida J, Imamura F, Osaki T, Nakatani T, Ogata Y, Yamamoto S, Namba Y, Otsuka T, et al. Randomized Phase II trial of paclitaxel and carboplatin followed by gemcitabine switch-maintenance therapy versus gemcitabine and carboplatin followed by gemcitabine continuationmaintenance therapy in previously untreated advanced nonsmall cell lung cancer. BMC Res Notes. 2013; 6:3.

21. Lu G, Ades AE. Combination of direct and indirect evidence in mixed treatment comparisons. Stat Med. 2004; 23:3105-24.

22. Dias S, Sutton AJ, Ades AE, Welton NJ. Welton. Evidence synthesis for decision making 2: a generalized linear modeling framework for pairwise and network metaanalysis of randomized controlled trials. Med Decis Making. 2013; 33:607-17.

23. Dias S, Welton NJ, Caldwell DM, Ades AE. Ades. Checking consistency in mixed treatment comparison meta-analysis. Stat Med. 2010; 29:932-44.

24. Zhu GQ, Shi KQ, Huang S, Wang LR, Lin YQ, Huang GQ, Chen YP, Braddock M, Zheng MH. Zheng. Systematic review with network meta-analysis: the comparative effectiveness and safety of interventions in patients with overt hepatic encephalopathy. Aliment Pharmacol Ther. 2015; 41:624-35.

25. Chaimani A, Higgins JP, Mavridis D, Spyridonos P, Salanti G. Salanti. Graphical tools for network metaanalysis in STATA. PLoS One. 2013; 8:e76654.

26. Salanti G, Ades AE, Ioannidis JP. Ioannidis. Graphical methods and numerical summaries for presenting results from multiple-treatment meta-analysis: an overview and tutorial. J Clin Epidemiol. 2011; 64:163-71. 
27. Smorenburg $\mathrm{CH}$, de Groot SM, van Leeuwen-Stok AE, Hamaker ME, Wymenga AN, de Graaf H, de Jongh FE, Braun JJ, Los M, Maartense E, van Tinteren H, Nortier JW, Seynaeve C. A randomized phase iii study comparing pegylated liposomal doxorubicin with capecitabine as firstline chemotherapy in elderly patients with metastatic breast cancer: Results of the omega study of the dutch breast cancer research group boog. Ann Oncol. 2014; 25:599-605.

28. Leone JP, Leone J, Vallejo CT, Pérez JE, Romero AO, Machiavelli MR, Romero Acuña L, Domínguez ME, Langui M, Fasce HM, Leone BA, Ortiz E, Iturbe J, et al. Sixteen years follow-up results of a randomized phase ii trial of neoadjuvant fluorouracil, doxorubicin, and cyclophosphamide (fac) compared with cyclophosphamide, methotrexate, and 5-fluorouracil (cmf) in stage iii breast cancer: Gocs experience. Breast Cancer Res Treat. 2014; 143:313-23.

29. Stockler MR, Harvey VJ, Francis PA, Byrne MJ, Ackland SP, Fitzharris B, Van Hazel G, Wilcken NR, Grimison PS, Nowak AK, Gainford MC, Fong A, Paksec L, et al. Capecitabine versus classical cyclophosphamide, methotrexate, and fluorouracil as first-line chemotherapy for advanced breast cancer. J Clin Oncol. 2011; 29:4498-504.

30. Cassier PA, Chabaud S, Trillet-Lenoir V, Peaud PY, Tigaud JD, Cure H, Orfeuvre H, Salles B, Martin C, Jacquin JP, Agostini C, Guastalla JP, Pérol D, et al. A phaseiii trial of doxorubicin and docetaxel versus doxorubicin and paclitaxel in metastatic breast cancer: Results of the erasme 3 study. Breast Cancer Res Treat. 2008; 109:343-50.

31. Evans TR, Yellowlees A, Foster E, Earl H, Cameron DA, Hutcheon AW, Coleman RE, Perren T, Gallagher CJ, Quigley M, Crown J, Jones AL, Highley M, et al. Phase iii randomized trial of doxorubicin and docetaxel versus doxorubicin and cyclophosphamide as primary medical therapy in women with breast cancer: An anglo-celtic cooperative oncology group study. J Clin Oncol. 2005; 23:2988-95.

32. Sledge GW, Neuberg D, Bernardo P, Ingle JN, Martino S, Rowinsky EK, Wood WC. Phase iii trial of doxorubicin, paclitaxel, and the combination of doxorubicin and paclitaxel as front-line chemotherapy for metastatic breast cancer: An intergroup trial (e1193). Journal of Clinical Oncology. 2003; 21:588-92.

33. Biganzoli L, Cufer T, Bruning P, Coleman R, Duchateau L, Calvert AH, Gamucci T, Twelves C, Fargeot P, Epelbaum R, Lohrisch C, Piccart MJ. Doxorubicin and paclitaxel versus doxorubicin and cyclophosphamide as first-line chemotherapy in metastatic breast cancer: The european organization for research and treatment of cancer 10961 multicenter phase iii trial. Journal of Clinical Oncology. 2002; 20:3114-21.

34. Jassem J, Pieńkowski T, Płuzańska A, Jelic S, Gorbunova V, Mrsic-Krmpotic Z, Berzins J, Nagykalnai T, Wigler N, Renard J, Munier S, Weil C; Central \& Eastern Europe and Israel Pacitaxel Breast Cancer Study Group. Doxorubicin and paclitaxel versus fluorouracil, doxorubicin, and cyclophosphamide as first-line therapy for women with metastatic breast cancer: Final results of a randomized phase iii multicenter trial. J Clin Oncol. 2001; 19:1707-15.

35. Wagstaff AJ, Ibbotson T, Goa KL. Goa. Capecitabine: a review of its pharmacology and therapeutic efficacy in the management of advanced breast cancer. Drugs. 2003; 63:217-36.

36. Silvestris N, Maiello E, De Vita F, Cinieri S, Santini D, Russo A, Tommasi S, Azzariti A, Numico G, Pisconti S, Petriella D, Lorusso V, Millaku A, et al. Update on capecitabine alone and in combination regimens in colorectal cancer patients. Cancer Treat Rev. 2010; 36:S46-55.

37. Walko CM, Lindley C. Lindley. Capecitabine: a review. Clin Ther. 2005; 27:23-44.

38. Daniele G, Gallo M, Piccirillo MC, Giordano P, D'Alessio A, Del Giudice A, La Porta ML, Perrone F, Normanno N, De Luca A. Pharmacokinetic evaluation of capecitabine in breast cancer. Expert Opin Drug Metab Toxicol. 2013; 9:225-35.

39. Molteni LP, Rampinelli I, Cergnul M, Scaglietti U, Paino AM, Noonan DM, Bucci EO, Gottardi O, Albini A. Capecitabine in breast cancer: the issue of cardiotoxicity during fluoropyrimidine treatment. Breast J. 2010; 16:S45-8.

40. Naughton M. Evolution of capecitabine dosing in breast cancer. Clin Breast Cancer. 2010; 10:130-5.

41. Dellapasqua S, Bertolini F, Bagnardi V, Campagnoli E, Scarano E, Torrisi R, Shaked Y, Mancuso P, Goldhirsch A, Rocca A, Pietri E, Colleoni M. Metronomic cyclophosphamide and capecitabine combined with bevacizumab in advanced breast cancer. J Clin Oncol. 2008; 26:4899-905.

42. Azuma Y, Hata K, Sai K, Udagawa R, Hirakawa A, Tohkin M, Ryushima Y, Makino Y, Yokote N, Morikawa N, Fujiwara Y, Saito Y, Yamamoto H. Significant association between hand-foot syndrome and efficacy of capecitabine in patients with metastatic breast cancer. Biol Pharm Bull. 2012; 35:717-24.

43. Yoshimoto N, Yamashita T, Fujita T, Hayashi H, Tsunoda N, Kimura M, Tsuzuki N, Yamashita H, Toyama T, Kondo N, Iwata H. Impact of prophylactic pyridoxine on occurrence of hand-foot syndrome in patients receiving capecitabine for advanced or metastatic breast cancer. Breast Cancer. 2010; 17:298-302.

44. Saif MW, Eloubeidi MA, Russo S, Steg A, Thornton J, Fiveash J, Carpenter M, Blanquicett C, Diasio RB, Johnson MR. Johnson. Phase I study of capecitabine with concomitant radiotherapy for patients with locally advanced pancreatic cancer: expression analysis of genes related to outcome. J Clin Oncol. 2005; 23:8679-87.

45. Ilyas S, Wasif K, Saif MW. Topical henna ameliorated capecitabine-induced hand-foot syndrome. Cutan Ocul Toxicol. 2014; 33:253-5.

46. Dong X, Liu A, Zer C, Feng J, Zhen Z, Yang M, Zhong L. siRNA inhibition of telomerase enhances the anti-cancer effect of doxorubicin in breast cancer cells. BMC Cancer. 2009; 9:133. 
47. Cai S, Thati S, Bagby TR, Diab HM, Davies NM, Cohen MS, Forrest ML. Localized doxorubicin chemotherapy with a biopolymeric nanocarrier improves survival and reduces toxicity in xenografts of human breast cancer. J Control Release. 2010; 146:212-8.

48. Stavridi F, Palmieri C. Efficacy and toxicity of nonpegylated liposomal doxorubicin in breast cancer. Expert Rev Anticancer Ther. 2008; 8:1859-69.

49. Rigatos SK, Tsavdaridis D, Athanasiadis A, Stathopoulos JG, Stathopoulos GP. Paclitaxel and liposomal doxorubicin (Caelyx) combination in advanced breast cancer patients: a phase II study. Oncol Rep. 2003; 10:1817-9.

50. Gebbia V, Mauceri G, Fallica G, Borsellino N, Tirrito ML, Testa A, Varvara F, Colombo A, Ferrera P. Pegylated liposomal doxorubicin with vinorelbine in metastatic breast carcinoma. A phase I-II clinical investigation. Oncology. 2002; 63:23-30.

51. Troso-Sandoval TA, Lichtman SM. Chemotherapy of ovarian cancer in elderly patients. Cancer Biol Med. 2015; 12:292-301.

52. Hu XC, Zhang J, Xu BH, Cai L, Ragaz J, Wang ZH, Wang BY, Teng YE, Tong ZS, Pan YY, Yin YM, Wu CP, Jiang ZF, et al. Cisplatin plus gemcitabine versus paclitaxel plus gemcitabine as first-line therapy for metastatic triplenegative breast cancer (cbcsg006): A randomised, openlabel, multicentre, phase 3 trial. Lancet Oncol. 2015; $16: 436-46$.

53. Jassem J, Pieńkowski T, Płuzańska A, Jelic S, Gorbunova V, Mrsic-Krmpotic Z, Berzins J, Nagykalnai T, Wigler N, Renard J, Munier S, Weil C; Central \& Eastern Europe and Israel Pacitaxel Breast Cancer Study Group. Doxorubicin and paclitaxel versus fluorouracil, doxorubicin, and cyclophosphamide as first-line therapy for women with metastatic breast cancer: Final results of a randomized phase iii multicenter trial. J Clin Oncol. 2001; 19:1707-15.

54. Baker J, Ajani J, Scotte F, Winther D, Martin M, Aapro MS, von Minckwitz G. Docetaxel-related side effects and their management. Eur J Oncol Nurs. 2009; 13:49-59.

55. Yuan Q, Han J, Cong W, Ge Y, Ma D, Dai Z, Li Y, Bi X. Docetaxel-loaded solid lipid nanoparticles suppress breast cancer cells growth with reduced myelosuppression toxicity. Int J Nanomedicine. 2014; 9:4829-46.

56. Yan M, Kumachev A, Siu LL, Chan KK. Chemoradiotherapy regimens for locoregionally advanced nasopharyngeal carcinoma: A Bayesian network metaanalysis. Eur J Cancer. 2015; 51:1570-9. 